\title{
INFLUÊNCIA DA INFORMAÇÃO ASSIMÉTRICA NA OBTENÇÃO DE CRÉDITO EM EMPRESAS CALÇADISTAS EM JUAZEIRO DO NORTE, CE
}

\author{
INFLUENCE OF ASYMMETRIC INFORMATION ON THE OBTENTION OF CREDIT IN \\ FOOTWEAR COMPANIES IN JUAZEIRO DO NORTE, CE
}

\author{
Amanda Teixeira da Silva \\ Universidade Regional do Cariri, Crato, CE, Brasil. \\ E-mail: amandaxiii@hotmail.com \\ Eliane Pinheiro de Sousa \\ Universidade Regional do Cariri, Crato, CE, Brasil. \\ E-mail: pinheiroeliane@hotmail.com
}

Recebido em: 25.01.2017 - Aceito em: 16.02.2017

\section{RESUMO}

Este estudo analisa a influência da assimetria de informação na obtenção de crédito para as micro e pequenas empresas calçadistas de Juazeiro do Norte, Ceará. Para isto, é feito um levantamento teórico acerca das características do mercado de crédito, informação assimétrica, e como esta interfere no funcionamento do mercado ocasionando o racionamento de crédito e dificultando seu acesso. Para a análise das evidências empíricas da assimetria de informação no mercado de crédito, foi realizada uma pesquisa de campo com gerentes das instituições financeiras do Banco do Nordeste, Banco do Brasil e Bradesco, e com os micro e pequenos empresários de calçados, que são os tomadores de crédito. Os resultados indicaram que as informações emitidas e recebidas entre as empresas tomadoras de crédito e os agentes financeiros estão em harmonia, o que minimiza a possibilidade de problemas com seleção adversa e risco moral.

PALAVRAS-CHAVE: Assimetria de informação; Crédito; Calçados.

\section{ABSTRACT}

This study analyzes the influence of the asymmetry of information on the obtention of credit for the micro and small footwear companies of Juazeiro do Norte, the state of Ceará. In order to achieve this objective, it has been conducted a theoretical survey of the characteristics of the credit market, on asymmetrical information, and how it interferes in the operation of the market, causing the rationing of credit and making its access more difficult. For the analysis of the empirical evidence, made up of survey with the managers of financial institutions such as Banco do Nordeste, 
Banco do Brasil and Bradesco, and with to the micro and small footwear businessmen, which are the borrowers. The results indicated that the information issued and received among the borrowing companies and the financial agents are in harmony, which minimizes the possibility of problems with adverse selection and moral risk.

KEYWORDS: Asymmetry of information; Credit; Footwear.

\section{INTRODUÇÃO}

Atualmente, o avanço tecnológico tornou a informação um bem inestimável, cada vez mais presente e obtido de maneira rápida e autônoma. Porém, também propiciou uma avalanche de dados e conhecimento que, dependendo da função, precisam ser filtrados ou simplificados. No cenário econômico, faz necessária a geração e a obtenção da informação de forma clara e eficiente, tornando-se um canal para o avanço tecnológico e econômico dos empreendimentos e atividades empresariais.

Quando a informação é um bem privado, ou seja, seu acesso ou obtenção é restrito, haverá um custo para obtê-la. Desta forma, essa informação não é completa, existindo imperfeição em sua circulação e obtenção. Assim, apresenta-se o fenômeno da informação assimétrica, que impede o funcionamento perfeitamente concorrencial do mercado. Neste caso, quando dois ou mais agentes econômicos estabelecem entre si uma transação econômica, em que uma das partes envolvidas detém informações superiores em relação à outra, há assimetria de informação.

O tema em questão, a princípio, foi analisado no estudo seminal desenvolvido por Akerlof (1970), que realizou uma investigação sobre relações entre qualidade e informação, como também suas implicações no funcionamento dos mercados. Utiliza como exemplo o mercado de carros usados, já que os compradores nesse mercado desconhecem a verdadeira qualidade dos automóveis. Demonstrou que a existência de diferentes qualidades de bens, associados à falta de informação dos compradores no mercado podem levar a uma diminuição de qualidade ou mesmo extinção deste.

Posteriormente, o conceito de assimetria de informação foi introduzido no estudo de diversos mercados. Stiglitz e Weiss (1981) trazem essa discussão para o mercado de crédito, fazendo uma análise sobre a existência de seu racionamento devido às informações assimétricas, e, com isso, diagnosticando o porquê do crédito ser concedido apenas a uma parcela da sua demanda.

De acordo com Aleem (1993) apud Azevedo e Shikida (2004), a assimetria de informações influencia tanto a oferta, já que o emprestador precisa obter o 
máximo de informações possíveis sobre o tomador de empréstimo, mas, dada a dificuldade, pode colocar em risco seu portfólio; quanto à demanda por crédito, visto que os demandantes não possuem pleno conhecimento sobre os termos dos contratos fornecidos pelos emprestadores. Para Albanez e Valle (2009), empresas com menor informação assimétrica têm mais facilidade de avaliação do seu risco por parte dos credores, permitindo aumentar a oferta de crédito.

Aliada a tais considerações, Vieira (2010) destaca que a assimetria de informação propicia uma elevação nos custos de intermediação financeira, que desviam recursos do uso produtivo, reduzindo o estoque de capital e o produto da economia e ocasionando uma diminuição do bem-estar social.

Em períodos de crises e escassez de créditos, estudos dessa natureza estão no foco de discussão tanto no meio acadêmico quanto no mercado. Apesar da relevância de se tratar dessa temática, há escassez na literatura de estudos empíricos que utilizem dados primários, coletados por meio de pesquisa de campo com instituições financeiras e tomadores de crédito. Portanto, este artigo contribui neste sentido.

O Brasil apresenta um elevado nível da atividade financeira, ao mesmo tempo em que deixa a desejar no que se refere ao sistema financeiro: crédito e financiamento muito reduzidos, caro e de difícil acesso, principalmente para aqueles menos favorecidos no que diz respeito à renda, afetando o crescimento dos empreendimentos em geral, principalmente, as micro e pequenas empresas (MPE's) (CARVALHO e ABRAMOVAY, 2004).

De acordo com o Banco Nacional de Desenvolvimento Econômico e Social (BNDES, 2016), foram desembolsados $R \$ 138.873$ milhões de financiamentos do sistema BNDES, em 2011, sendo que as empresas de grande porte tiveram uma participação de $57,7 \%$, enquanto as micro e pequenas empresas absorveram $25,4 \%$.

Para Santos (2004), elevados níveis de informalidade e as precárias informações contábeis dos pequenos negócios são elementos que potencializam a assimetria de informação nas operações de crédito desse mercado.

O segmento dos pequenos negócios é um dos principais pilares de sustentação da economia nacional, tanto pelo número de estabelecimentos, quanto pela sua capacidade de gerar empregos. Conforme SEBRAE (2014), o número de micro e pequenas empresas no Brasil são cerca de 9 milhões, o que corresponde mais da metade dos empregos formais. Quanto ao número de empresas, as MPE's representaram $98 \%$ e $99 \%$ do total de empresas formalizadas, respectivamente, nas atividades de serviços e de comércio em 2011. Em relação ao emprego, as MPE's representavam 44\% dos empregos formais em serviços e aproxima- 
damente $70 \%$ dos empregos gerados no comércio. Outro dado importante é que as MPE'S atingiram 27\% do total do Produto Interno Bruto (PIB) nacional em 2011.

O crédito desempenha fundamental relevância para o microempreendedor. Ele necessita de capital para investir, seja para montar ou melhorar seu negócio, como também requer capital de giro para suprir as defasagens de caixa da empresa, objetivando atender as necessidades operacionais. Neste contexto, a informação é um dos fatores essenciais na obtenção de crédito, principalmente para esse segmento de mercado que é crescente e que sofre com a restrição do mesmo para seu desenvolvimento. Portanto, com base nessas considerações, reveste-se de importância estudos que contemplam essas questões.

Neste sentido, este estudo se propõe analisar a influência da informação assimétrica no mercado de crédito para as micro e pequenas empresas de calçados na cidade cearense de Juazeiro do Norte. Especificamente, pretende-se relacionar a teoria da informação assimétrica com a dificuldade na obtenção de crédito; e analisar evidências empíricas, pelas óticas da oferta e da demanda, da assimetria de informação no mercado de crédito para as MPE's de calçados em Juazeiro do Norte.

\section{FUNDAMENTAÇÃO TEÓRICA}

\subsection{Teoria da agência e informação assimétrica}

De acordo com Jensen e Meckling (1976), uma relação de agência refere-se a um contrato entre duas partes, em que o principal delega um dado serviço que envolve alguma tomada de decisão para o agente. Como ambas as partes são maximizadoras de utilidade, acredita-se que nem sempre o agente vai agir no melhor interesse do principal. Desta forma, segundo Eisenhardt (1989), a teoria da agência se preocupa em resolver dois problemas que podem ocorrer nas relações de agência. O primeiro surge quando os desejos ou metas do principal forem conflitantes com os do agente, além de ser difícil ou caro para o principal verificar se o agente se comportou adequadamente. $O$ segundo aparece quando o principal e o agente possuem ações diferentes por causa das distintas preferências em relação ao risco.

Baseada na economia da informação, a teoria da agência desenvolveu-se em duas linhas: positivista e agente-principal. As duas vertentes compartilham uma unidade comum de análise: o contrato entre o principal e o agente, porém diferem em seu rigor matemático, variável dependente e estilo. A teoria positivista identifica várias alternativas de contrato e a teoria do agente-principal indica qual 
contrato é o mais eficiente em diferentes níveis de incerteza de resultado, aversão ao risco e informação (JENSEN, 1983; EISENHARDT, 1989; MARTINEZ, 1998).

Além de diagnosticar a natureza dos problemas presentes nas relações contratuais, a teoria da agência propõe mecanismos que garantem a construção de contratos que sejam o mais eficiente possível para a solução de problemas resultantes da relação entre principal e agente (MARTINEZ, 1998).

A teoria da agência traz também duas contribuições específicas ao pensamento organizacional. A primeira se refere ao tratamento da informação. Na teoria da agência, a informação é considerada como uma mercadoria: tem um custo e pode ser comprada. Isso implica que as organizações podem investir em sistemas de informação para controlar o oportunismo dos agentes. A segunda diz respeito às suas implicações de risco. Considera-se que as empresas têm futuros incertos e que o futuro é apenas parcialmente controlado pelos membros da organização. Os efeitos ambientais, como a regulamentação governamental, a emergência de novos concorrentes e a inovação técnica podem afetar os resultados. A incerteza é vista em termos de trade-offs de risco / recompensa não apenas devido à incapacidade de pré-planejar. A implicação é que a incerteza de resultado associada às diferenças na disposição de aceitar o risco deve influenciar os contratos entre principal e agente (EISENHARDT, 1989).

A partir da interação entre principal e agente, surgem problemas de conflito de agência oriundos da assimetria da informação (ROCHA et al., 2012). Segundo Pindyck e Rubinfeld (2013), a informação assimétrica ocorre quando a informação é incompleta, ou seja, quando compradores e vendedores possuem informações distintas sobre uma transação.

Os principais problemas resultantes da informação assimétrica são a seleção adversa e o risco moral. A seleção adversa surge quando produtos de qualidades diferentes são vendidos pelo mesmo preço, pois compradores e vendedores não têm como determinar a real qualidade do produto. No caso do risco moral (ex-post), pode ser denominado como ações ocultas dos agentes (tomadores), do principal, se os interesses do agente e do principal não estiverem alinhados. $O$ agente normalmente tem mais informações sobre suas ações ou intenções do que o principal, porque, em geral, o principal não pode monitorar perfeitamente o agente (AKERLOF, 1970).

No sistema financeiro, conforme Frascaroli et al. (2010), a seleção adversa decorre da informação assimétrica obtida pelos bancos a respeito dos projetos de investimentos dos agentes. Esse problema impõe um limite à taxa de juros que pode impedir o equilíbrio do mercado de capitais. Desta forma, os bancos não 
conseguem distinguir perfeitamente entre projetos com baixo risco e com alto risco ao financiarem os agentes que submetem seus projetos. O risco moral ocorre devido aos altos custos ou à incapacidade operacional dos bancos de monitorarem as ações dos agentes após os contratos de concessão de crédito.

\subsection{Assimetria de informação e racionamento de crédito}

Segundo Stiglitz e Weiss (1981), o mercado de crédito se caracteriza pela existência de assimetrias de informação e problemas do tipo principal-agente. Esses problemas levam o mercado a soluções que não são ótimas, no que diz respeito ao sentido econômico do termo, em que se espera a igualdade entre a oferta e a demanda por via do mecanismo dos preços.

O conceito de equilíbrio com racionamento para os mercados de crédito mostra o seguinte pressuposto: em equilíbrio, os mercados são caracterizados pelo racionamento de crédito de tal forma que, não há como igualar a demanda e a oferta de empréstimos, ocasionando dessa forma o racionamento da oferta. Esse racionamento, no entanto, é a solução mais eficiente encontrada pelos bancos como estratégia para evitar o aumento do risco da sua carteira de empréstimos (STIGLITZ e WEISS, 1981).

De acordo com Maia (2009), o racionamento de crédito se caracteriza pelo fato de o ajuste entre a oferta e a demanda se dá pela restrição da quantidade de crédito cedido e não por meio da variação da taxa de juros. Para ele, existe uma margem de insatisfeitos, que se enquadram aqueles que não obtêm acesso ao crédito mesmo dispostos a pagar a taxa de juros vigente no mercado.

Stiglitz e Weiss (1981) propõem que a existência de informações assimétricas por parte dos bancos em relação aos devedores conduz a processos de seleção adversa por meio das taxas de juros: os devedores que aceitam pagar maiores taxas de juros são aqueles que oferecem maiores riscos de inadimplência ao banco. Um aumento das taxas de juros atrai a carteira dos devedores de maior risco, ao mesmo tempo em que expulsa os de risco menor. Assim, as taxas de juros sinalizam para o banco o risco corrente de sua carteira de empréstimos.

$\mathrm{Na}$ concepção de Matias (2009), a seleção adversa ocorre em virtude do conjunto de informações sobre o proponente de crédito ser incompleto ou incerto, ou devido o financiador utilizar métodos de pesquisa ou fontes de informação que não sejam adequadas para a avaliação do risco de financiamento em análise. $A$ minimização dos problemas resultantes da seleção adversa por meio de acréscimos na taxa de juro poderá ocorrer que, a partir de um dado valor, o aumento da 
taxa conduza à diminuição da rentabilidade esperada do banco, já que este deixará de ter incentivos para aumentar. Para uma dada taxa de juro, se a demanda exceder a oferta de crédito, deverá ocorrer mesmo um racionamento de clientes.

Braga (1999) apresenta o problema de assimetria de informação no mercado de crédito de um ponto de vista ex ante, ou seja, antes que os contratos entre credor e devedor sejam firmados. Sua ocorrência, entretanto, também possui implicações ex post - aquelas referentes ao efetivo cumprimento dos contratos. Nesse caso, a informação assimétrica levará a problemas de risco moral, associados à inadimplência, cuja solução para evitar esse tipo de problema passa pelo monitoramento de contratos do banco, a fim de evitar condutas do devedor que resultem em risco moral. As técnicas de monitoramento são corroboradas por Matias (2009) como estratégias para reduzir os problemas advindos da informação assimétrica no mercado de crédito na fase pós-contratual. Para este autor, as técnicas de monitoramento consistem em se colocar em prática um conjunto de mecanismos que minimizam os custos de agência.

Vale ressaltar que, conforme Zica e Martins (2008), a insuficiência de garantias reais consiste no principal fator que inibe o acesso ao crédito para os empresários de pequeno porte. Esse problema também é percebido pelas instituições financeiras, que pretendem ofertar crédito e ampliar suas carteiras de empréstimos, porém se defrontam com a mesma falta de informações e garantias confiáveis por parte das firmas.

O risco moral existente nas transações e a exigência de garantias gera uma situação de restrição de crédito, que se torna mais evidente nas micro e pequenas empresas brasileiras. Esses pequenos empreendedores não conseguem obter a quantidade desejada de crédito, uma vez que o prêmio de risco requerido pode ser alto ou a quantia emprestada pode ser limitada, assim como não são capazes de oferecer ou não dispõem de garantias reais que atendam às exigências dos emprestadores (CHEIN, SILVA, 2014).

Além da falta de garantias reais, segundo Chaves (2009), há outros motivos responsáveis pelo baixo interesse dos bancos em financiar micro e pequenas empresas. Dentre eles, destaca-se a presença de altos custos de transação, baixa dimensão das operações de financiamento, elevados níveis de informalidade, inexistência de informações financeiras adequadas à avaliação de risco e operações de financiamento, potencializando a assimetria de informações nas operações de crédito e obrigando as instituições bancárias a estarem sempre analisando um grande conjunto de informações para avaliar a capacidade de pagamento do cliente. 
Para Aoki e Badalotti (2014), no tocante às linhas de crédito públicas, as microempresas enfrentam fortes entraves para ter acesso a tais linhas de crédito, podendo ser atribuída à falta de assessoria e de uma rede de apoio que possa servir como mediadora dessas políticas de desenvolvimento. Tais dificuldades indicam que apesar dessas políticas terem expandido as possibilidades e modalidades de crédito e financiamento ainda geram um grande desconhecimento para as microempresas.

\section{METODOLOGIA}

\section{1 Área de estudo e seu mercado calçadista}

O estudo foi realizado no município de Juazeiro do Norte, que se encontra situado na Região Metropolitana do Cariri, no Sul do estado do Ceará. Segundo o Instituto de Pesquisa e Estratégia Econômica do Ceará (IPECE, 2016), este município distancia, em linha reta, da capital em $396 \mathrm{~km}$, possui área absoluta de 248,55 km² e população constituída por 249.939 habitantes, em 2010, representando o terceiro município mais populoso do Ceará. Em termos econômicos, registrou PIB per capita de $R \$ 12.328,00$ em 2013, sendo que o setor de serviços foi responsável por $86,56 \%$ do PIB, a indústria representou uma participação de $12,96 \%$ e a agropecuária de $0,48 \%$.

A cidade de Juazeiro do Norte é marcada por uma intensa religiosidade, que atrai anualmente mais de um milhão de romeiros. Para satisfazer a demanda local e de municípios circunvizinhos por calçados, passou-se a fabricar, a princípio, sandálias regionais. $\mathrm{O}$ arranjo produtivo de calçados em Juazeiro do Norte é constituído, em sua maioria, por micro e pequenas empresas com baixa intensidade tecnológica, tendo em seu primórdio o couro como matéria-prima, mas ganhou um novo dinamismo com a inserção de materiais sintéticos derivados do petróleo, como Policloreto de vinila (PVC) e Copolímero de etileno e vinil acetato (EVA), diferenciando-se de outros arranjos no Sul e Sudeste, em que sua produção está essencialmente vinculada ao setor coureiro (COSTA, 2007). Segundo Feitosa e Sousa (2013), o surgimento desse arranjo pode ser atribuído a um fator histórico, que se originou com os artesanatos de couro para suprir as necessidades do vaqueiro do semiárido e um fator territorial que se refere ao dinamismo do comércio do município devido à posição geográfica e ao fluxo de romeiros.

De acordo com Costa (2007), o mercado calçadista de Juazeiro do Norte é compartimentalizado conforme o porte do estabelecimento. As micro e pequenas 
empresas comercializam produtos, cuja matéria-prima (PVC reciclado e placa de EVA) é fabricada localmente pelas empresas maiores, ao passo que essas últimas se especializam em produtos de maior valor agregado, que são vendidos em âmbito nacional e internacional.

\subsection{Natureza dos dados e tamanho da amostra}

O estudo contou com levantamento bibliográfico acerca da temática, feito por meio de livros, artigos científicos, entre outros. Ademais, empregaram-se dados primários, obtidos pela pesquisa de campo, realizada em maio e junho de 2011, constituída pela aplicação de questionários com os micro e pequenos empresários de calçados (tomadores de crédito) e aos gerentes das instituições financeiras (emprestadores) do Banco do Brasil, Banco do Nordeste (BNB) e Bradesco.

A qualificação dos estabelecimentos quanto ao porte pode ser feita mediante o faturamento da empresa, o total do ativo, o número de funcionários empregados etc. Neste estudo, considerou-se a classificação adotada pelo SEBRAE (2014), que define o porte de acordo com a quantidade de pessoas ocupadas, sendo classificada como micro empresa, a que possui até nove, e pequena empresa, a que possui de dez a 49 .

A seleção da amostra foi feita junto às empresas cadastradas no SINDINDÚSTRIA de Juazeiro do Norte, que forneceu o número de micro e pequenas empresas cadastradas, totalizando 51 estabelecimentos.

Para se determinar o tamanho da amostra para populações finitas por meio da amostragem aleatória simples, conforme Fonseca e Martins (1996), utiliza-se a fórmula: $n=\frac{z^{2} \cdot p \cdot q \cdot N}{d^{2} \cdot(n-1)+z^{2} \cdot p \cdot q}$

em que: $\mathrm{n}=$ tamanho da amostra; $\mathrm{z}=$ abscissa da normal padrão; $\mathrm{p}=$ estimativa da proporção da característica pesquisada no universo; $q=1-p ; N=$ tamanho da população; $d$ = erro amostral.

Considerando a presença de 51 empresas associadas ao SINDINDÚSTRIA, um erro de estimação de $10 \%(d=0,1)$; abscissa da normal padrão $z=1,64$, ao nível de confiança de $90 \%$ e $p=q=0,5$, obteve-se uma amostra formada por 29 empresas entrevistadas.

Para atender os objetivos propostos, empregou-se análise tabular e descritiva dos dados obtidos. 


\section{RESULTADOS E DISCUSSÃO}

Os resultados da assimetria de informação no mercado de crédito para as MPE's de calçados em Juazeiro do Norte - CE são expostos tanto pela ótica da oferta (três instituições financeiras pesquisadas: Banco do Brasil, Banco do Nordeste e Bradesco), quanto pela ótica da demanda (29 empresas tomadoras de crédito entrevistadas).

\subsection{Posição das instituições financeiras}

Para que as empresas venham ter a concessão de crédito, todas as instituições financeiras dizem necessário ser cliente da agência, pois a mesma tem um pouco mais de conhecimento sobre o histórico financeiro, o que diminui a incerteza e facilita a tomada de decisão quanto à liberação do crédito. Ademais, os que ainda não eram clientes podem passar a ser, propiciando ganhos e vantagens para a agência, pois o aumento de clientes poderá ser beneficiado com a venda de outros produtos e serviços do banco.

Para que a instituição financeira libere o crédito, ela precisa se precaver que o tomador de crédito, no caso as empresas de calçados, honre com seu compromisso, e possua condições suficientes para isso. Dessa forma, são exigidos alguns documentos, como ficha de cadastro, cadastro nacional da pessoa jurídica (CNPJ), relação de faturamento ou demonstrações contábeis, que são documentos necessários para todas as três instituições pesquisadas. Ademais, comprovantes de renda e de bens são também importantes e requeridos por duas das três instituições visitadas.

O banco procura dificultar que o tomador oculte informações pré-contratuais por meio do maior número de informações sobre o cliente. Assim, com o intuito de reduzir o risco moral, são requeridos comprovantes de renda, como declaração de renda, análise de conta corrente. Este mecanismo foi sugerido no estudo desenvolvido por Azevedo e Shikida (2004). Portanto, com base na pesquisa de campo, verificou-se que duas das três instituições pesquisadas exigem declaração de renda, e apenas uma faz análise de conta corrente. Outro documento exigido em um dos bancos é o formulário de perfil econômico, em que se tem um levantamento da capacidade financeira do cliente.

Quanto à comprovação de bens, para se conhecer os principais bens que constituem o patrimônio do tomador, torna-se necessário um maior número de elementos com o intuito de facilitar a previsão da sua capacidade de saldar a dívida no futuro. Tais informações são fundamentais para a liberação do crédito, contribuindo para reduzir as chances de ocorrer alguma forma de seleção adversa ou risco moral. Conforme o 
levantamento de dados primários, observou-se que as três instituições entrevistadas solicitam a escritura do imóvel e o documento de propriedade do veículo, e duas instituições requerem também o documento de propriedade de máquinas.

Os dados coletados nas três instituições entrevistadas indicam que todas elas fazem consulta ao SPC (Serviço de Proteção ao Crédito) e à SERASA (Centralização de Serviços dos Bancos) com o intuito de prever um possível problema de seleção adversa. Ademais, duas instituições também realizam outros tipos de consulta como SCR (Sistema de Informações de Crédito do Banco Central) e CADIN (Cadastro Informativo de créditos não quitados do setor público federal). O SCR consiste em um banco de dados sobre operações com características de crédito alimentado mensalmente pelas instituições financeiras e o CADIN possui um banco de dados que contém os nomes de pessoas tanto físicas quanto jurídicas com obrigações pecuniárias vencidas e não pagas aos órgãos e entidades da Administração Pública Federal.

Todas as instituições pesquisadas avaliam o formulário de cadastro do cliente para a liberação de crédito eficiente. Mesmo com essa medida, porém, o problema da seleção adversa e do risco moral pode não ser totalmente descartado, visto que o tomador de empréstimo pode omitir informações importantes ao preencher esse cadastro, como informações negativas a respeito do tomador que poderiam até colocar em risco a liberação do crédito se fossem esclarecidas. A esse respeito, segundo Chaves (2009), a inexistência de informações financeiras adequadas à avaliação de risco e operações de financiamento pode potencializar a assimetria de informações nas operações de crédito, desmotivando os bancos a financiarem as micro e pequenas empresas.

Os bancos exigem algumas taxas e serviços para a concessão do crédito, como seguro de propriedade e imposto sobre operações financeiras (IOF), que são requeridos por duas das três instituições pesquisadas. Além disso, o cheque especial e outras taxas e serviços também são solicitados por uma das três instituições pesquisadas.

Os financiamentos anteriores dos possíveis tomadores são analisados por $66,67 \%$ das instituições, ou seja, por duas das três instituições financeiras. Segundo Azevedo e Shikida (2004), essa prática desempenha papel importante, pois ao verificar o histórico de liquidez do tomador ao mesmo ou a outro banco identificam-se possíveis débitos pendentes, o que pode levar a restrição do novo crédito por aparentar risco já que não conseguiu até então cumprir com seus compromissos. A outra instituição financeira diz que é o próprio cliente que fornece a relação e/ou autorização para pesquisa.

De acordo com a pesquisa realizada, os três agentes financeiros entrevistados apresentam $75 \%$ de conhecimento sobre seus clientes. Esse resultado evidencia que os agentes financeiros não conhecem totalmente os clientes. Para 
Azevedo e Shikida (2004), a presença de informações desconhecidas pelas instituições pode conter dados importantes que teriam de ser do conhecimento do banco e que auxiliaria na segurança do retorno esperado.

Das instituições pesquisadas, todas afirmaram que não existem segmentos específicos de empresas tomadoras de crédito que apresentam maior credibilidade aos agentes financeiros. Segundo as instituições financeiras entrevistadas, não há diferença com relação à taxa de inadimplência entre micro e pequena empresa.

Dentre as causas de inadimplência por parte das empresas tomadoras de crédito apontadas pelas instituições, encontram-se o risco de mercado, fraudes e questões de cunho administrativo. Com relação aos procedimentos utilizados pela instituição, em caso de inadimplência, tem-se a cobrança, e a cobrança judicial, quando cabível. Para evitar esse tipo de problema, que resultem em risco moral, Braga (1999) e Matias (2009) sugerem o monitoramento de contratos do banco.

As principais formas de garantir o recebimento do capital emprestado pelas instituições consistem na negociação da dívida e na execução da garantia segundo duas das três instituições pesquisadas. A prorrogação do saldo devedor e o acompanhamento de crédito junto ao cliente também são apontados por uma das três instituições visitadas como uma forma de assegurar o recebimento do empréstimo. Para Zica e Martins (2008), a falta de garantias confiáveis por parte das firmas é um problema percebido pelas instituições financeiras, que limita a oferta de crédito e ampliação de suas carteiras de empréstimos.

No tocante à taxa de juros aplicada e ao prazo de pagamento do financiamento, varia de acordo com cada negócio, segundo as instituições financeiras entrevistadas. Na concepção de Stiglitz e Weiss (1981), uma elevação das taxas de juros atrai a carteira dos devedores de maior risco e simultaneamente expulsa os de risco menor. Desta forma, as taxas de juros apontam o risco corrente da carteira de empréstimos do banco. Para Frascaroli et al. (2010), o problema da seleção adversa impõe um limite à taxa de juros que pode impedir o equilíbrio do mercado de capitais.

\subsection{Posição das empresas tomadoras de crédito}

De acordo com os dados colhidos na pesquisa de campo, a faixa etária dos tomadores de crédito que apresentou maior frequência (correspondente a $34,48 \%$ ) está situada entre 46 a 55 anos; e nenhum entrevistado possui mais de 65 anos. Dos 29 entrevistados, quatro se encontram na faixa etária entre 15 a 25 anos. Segundo Camargo e Reis (2005), a assimetria de informação deve ser maior para os jovens, pois a experiência revela parte de suas características produtivas. 
No que diz respeito à naturalidade, a maioria dos empresários de calçados pesquisados é proveniente do estado do Ceará, sendo 58,62\% naturais de Juazeiro do Norte, e apenas 6,90\% vindos de outros Estados.

Em relação ao nível de instrução, os dados primários coletados indicam que há predominância de proprietários de empresas de calçados com ensino médio completo (44,82\%). Conforme Azevedo e Shikida (2004), um maior nível de escolaridade pode contribuir para um menor nível de assimetria de informação entre tomadores e agentes financeiros, minimizando as dificuldades de acesso às instituições financeiras, modo de funcionamento e normas. Essa relação inversa entre escolaridade e assimetria de informação também é corroborada por Camargo e Reis (2005) ao verificarem que a assimetria de informação deve ser maior para os semiqualificados (aqueles com escolaridade entre 4 e 10 anos) do que os com 11 anos de estudo ou mais.

De acordo com a pesquisa realizada com as empresas de calçados em Juazeiro do Norte, tanto existem empresas com menos de cinco anos de funcionamento como algumas delas funcionam há mais de 20 anos no mercado, produzindo, em sua maioria, sandálias femininas, sendo o PVC, o EVA, a borracha microporosa e o couro sintético como as principais matérias-primas utilizadas.

Outra questão também investigada diz respeito ao número de vezes que o proprietário da empresa tentou tomar crédito bancário. Os dados revelam que parcela majoritária dos entrevistados (62,07\%) não tentou nenhuma vez, justificando nunca ter precisado ou desistido da ideia diante da dificuldade em consegui-lo. Em contrapartida, dos 29 proprietários das empresas calçadistas, quatro deles $(13,79 \%)$ recorreram ao crédito bancário mais de duas vezes.

A maioria dos empresários alegou ser o capital de giro a razão responsável pela tomada de crédito. Ao serem questionados sobre o que poderia ser feito para facilitar o acesso ao crédito, $60,87 \%$ dos empresários disseram ser a redução da burocracia; $21,74 \%$ atribuíram à redução dos juros e 8,69\% apontaram a redução das taxas e impostos e maior prazo de pagamento.

Das empresas que tentaram o crédito bancário (apenas 37,93\% das entrevistadas), a proposta foi aceita em $90,91 \%$ dos casos. Os motivos alegados teriam sido por conta do tamanho do empréstimo, já que as instituições têm inclinação por empréstimos de maior valor para justificar os custos envolvidos, como também falta de garantias reais. Em conformidade com Zica e Martins (2008) e Chein e Silva (2014), a insuficiência de garantias reais que atendam às exigências dos emprestadores consiste no principal fator que inibe o acesso ao crédito para os empresários de pequeno porte. 
Ademais, os dados pesquisados mostram que $63,64 \%$ das empresas entrevistadas procuram o Banco do Nordeste na concessão de crédito, pois, segundo tais empresas, essa instituição financeira oferece melhores condições e facilidades. Em seguida, o Banco do Brasil é escolhido por 27,27\%, e 9,09\% optam pelo Bradesco. Esses dados sinalizam que as empresas calçadistas preferem tomar crédito em instituições públicas. Segundo Aoki e Badalotti (2014), embora linhas de crédito públicas, como Programa de Geração de Emprego e Renda (Proger) e BNDES/Finame, seja um poderoso instrumento de políticas públicas de inclusão social que promovam o desenvolvimento para o município e região, as microempresas enfrentam fortes entraves para ter acesso a tais linhas de crédito, podendo ser atribuída à falta de assessoria e de uma rede de apoio que possa servir como mediadora dessas políticas de desenvolvimento.

Em relação aos documentos e comprovantes exigidos pelas instituições financeiras para a concessão de crédito, de um modo geral, as respostas são condizentes com a posição das instituições, ou seja, os tomadores estão cientes que se deve cumprir com as exigências e a documentação solicitada para obter o crédito (Tabela 1).

Tabela 1 - Posição dos tomadores de crédito respondentes quanto aos documentos (A), ao comprovante de renda $(B)$ e aos bens $(C)$ exigidos pelas instituições financeiras para a liberação de financiamento.

\begin{tabular}{|c|c|c|c|c|c|}
\hline $\begin{array}{l}\text { Documentos } \\
\text { (A) }\end{array}$ & Qtde & $\begin{array}{l}\text { Comprovante de renda } \\
\text { (B) }\end{array}$ & Qtde & $\begin{array}{l}\text { Comprovante de } \\
\text { bens } \\
\text { (C) }\end{array}$ & Qtde \\
\hline Ficha de cadastro & 11 & $\begin{array}{c}\text { Formulário de } \\
\text { características } \\
\text { socioeconômicas do } \\
\text { proprietário }\end{array}$ & 6 & Escritura do imóvel & 5 \\
\hline CNPJ & 11 & Declaração de renda & 9 & $\begin{array}{l}\text { Documento de } \\
\text { propriedade do } \\
\text { veículo }\end{array}$ & 5 \\
\hline $\begin{array}{c}\text { Relação de } \\
\text { faturamento ou } \\
\text { demonstrações } \\
\text { contábeis }\end{array}$ & 10 & $\begin{array}{l}\text { Análise de conta } \\
\text { corrente }\end{array}$ & 5 & $\begin{array}{l}\text { Documento de } \\
\text { propriedade de } \\
\text { maquinas }\end{array}$ & 1 \\
\hline $\begin{array}{l}\text { Comprovante de } \\
\text { renda }\end{array}$ & 8 & Outros & 0 & Outros & 0 \\
\hline $\begin{array}{l}\text { Comprovante de } \\
\text { bens }\end{array}$ & 9 & - & - & - & - \\
\hline Outros & 1 & - & - & - & - \\
\hline
\end{tabular}


Quanto às taxas e serviços cobrados pelas instituições financeiras, sobressai o Imposto sobre Operações Financeiras (IOF) e o cheque especial, conforme sete e seis tomadores de crédito entrevistados, respectivamente.

O Gráfico 1 e a Tabela 2 mostram as principais evidências de como a assimetria de informações influencia o mercado de crédito para as empresas calçadistas de Juazeiro do Norte - CE. O Gráfico 1 analisa o nível de conhecimento em termos percentuais entre instituição financeira e MPE em relação uma a outra segundo a concepção dos empresários.

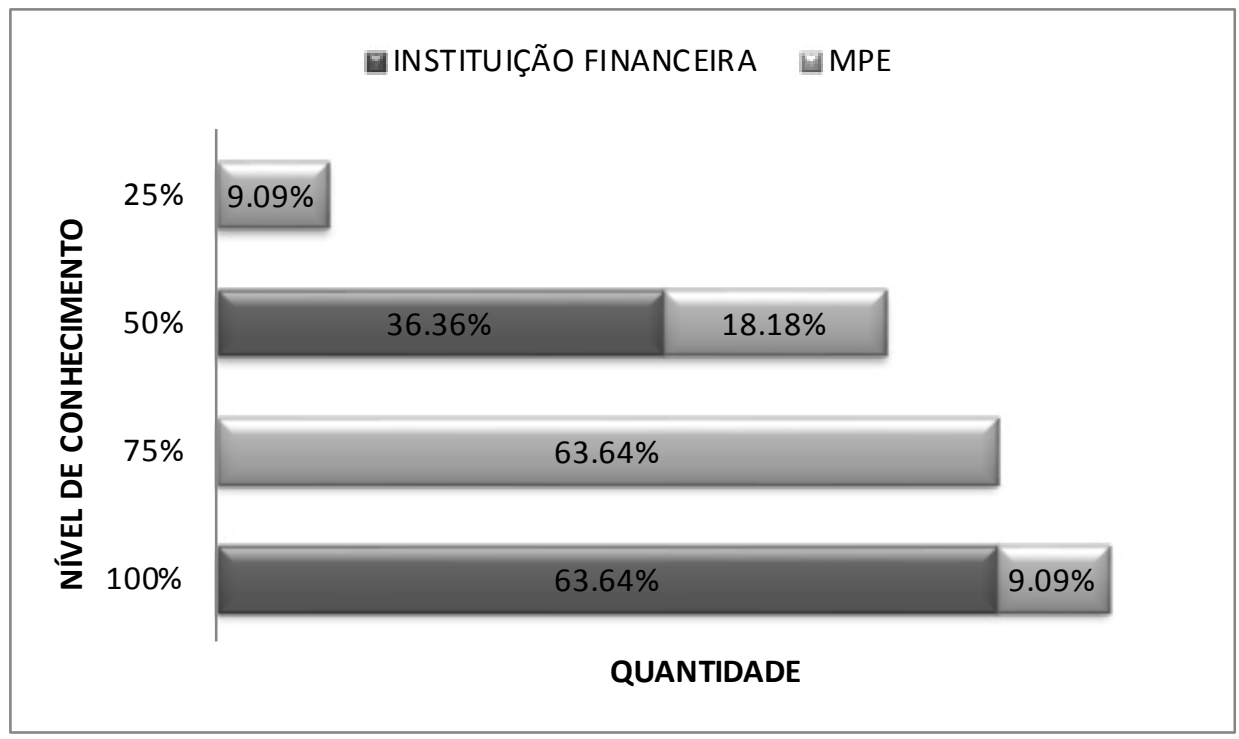

Gráfico 1 - Nível de conhecimento em termos percentuais entre instituição financeira e MPE em relação uma a outra segundo os empresários Fonte: Dados da pesquisa.

Com base neste gráfico, verifica-se que $63,64 \%$ dos entrevistados dizem ter $75 \%$ de conhecimento da instituição financeira, porém dificilmente os clientes teriam conhecimento absoluto de todas as normas do banco. Para 63,64\% dos empresários, o banco tem $100 \%$ de conhecimento sobre sua capacidade de pagamento, ao passo que $9,09 \%$ dos entrevistados alegam ter $100 \%$ de conhecimento sobre a instituição financeira que lhe concede o crédito.

A partir da Tabela 2, observa-se que $100 \%$ das instituições financeiras precisam da relação de faturamento ou demonstrações contábeis para a aprovação do crédito, e 90,91\% dos tomadores de crédito estão cientes disto. Sendo assim, nesse ponto, não se percebe indício de assimetria de informação entre as partes. 
Tabela 2 - Contraposição das informações coletadas (em termos percentuais) junto aos empresários e aos gerentes das instituições financeiras, que caracterizam a assimetria na concessão de crédito.

\begin{tabular}{ccc}
\hline Documentos exigidos/ atribuições & Instituição (\%) & Empresa (\%) \\
\hline Ficha de cadastro & 100,00 & 100,00 \\
CNPJ & 100,00 & 100,00 \\
Relação de faturamento ou demonstrações contábeis & 100,00 & 90,91 \\
Comprovante de renda & 66,67 & 72,73 \\
Comprovante de bens & 66,67 & 81,82 \\
Formulário de características do proprietário & 0,00 & 54,54 \\
Declaração de renda & 66,67 & 81,82 \\
Análise de conta corrente & 33,33 & 45,45 \\
Escritura do imóvel & 100,00 & 45,45 \\
Documento de propriedade do veículo & 100,00 & 45,45 \\
Documento de propriedade de máquinas & 66,67 & 9,09 \\
Seguro de vida & 0,00 & 27,27 \\
Seguro de propriedade & 66,67 & 27,27 \\
Taxa de comissão bancária (TAXA FLAT) & 66,67 & 63,64 \\
Chposto sobre operação financeira (IOF) & 33,33 & 54,54 \\
Cheque especial & 0,00 & 36,36 \\
\hline
\end{tabular}

Fonte: Dados da pesquisa.

Em alguns quesitos, porém, os tomadores apresentam falta de conhecimento, em que se tem o percentual da empresa bem abaixo da instituição, como, por exemplo, documento de propriedade de máquinas e seguro de propriedade. Possivelmente essa falta de informação esteja associada ao nível de escolaridade, e que quanto maior o nível de instrução, maior a facilidade de discernir contratos e absorver esclarecimentos.

No mercado de crédito, em um lado, estão as instituições financeiras que cuidam em tomar providências para que o seu investimento tenha um retorno. Em contrapartida, os tomadores de crédito, neste contexto, devem diminuir a assimetria de informação a respeito dos contratos para não comprometer seu capital. 


\section{CONSIDERAÇÕES FINAIS}

Este estudo teve como enfoque principal analisar a assimetria de informação no mercado de crédito para as micro e pequenas empresas calçadistas de Juazeiro do Norte. A partir do embasamento teórico, verifica-se a importância das MPE's na economia nacional, e o difícil e custoso acesso ao crédito por parte destas, tendo entre outros motivos alegados pelos bancos, os altos custos de transação e a falta de garantias reais.

A assimetria de informação, por sua vez, interfere no mercado de crédito de maneira que uma das partes envolvidas detém informações superiores em relação à outra, causando o problema da seleção adversa e do risco moral.

Neste contexto, verificou-se que a relação entre as empresas tomadoras de crédito e os agentes financeiros não é, de modo geral, de imperfeita informação, ou seja, as informações emitidas e recebidas estão em harmonia, o que reduz a possibilidade de problemas com seleção adversa e risco moral. Ressalta-se, porém, o fato de se tratar de uma pequena amostra resultante da pesquisa, e que essa situação pode ocorrer de forma diferenciada levando em conta outras abordagens. Portanto, é imprescindível que outros estudos empíricos sejam realizados para se aprimorar a discussão a respeito dessa temática.

\section{REFERÊNCIAS}

Akerlof, G. (1970) "The market for "lemons": quality, uncertainly and the market mechanism."Quartely Journal of Economics, v. 84, p. 488-500.

Albanez, T.; Valle, M. R. (2009) "Impactos da assimetria de informação na estrutura de capital de empresas brasileiras abertas." Revista Contabilidade \& Finanças. USP, São Paulo, v. 20, n. 51, p. 6-27.

Amaral Júnior, J. B.; Távora Junior, J. L. (2010) "Uma análise do uso de redes neurais para a avaliação do risco de crédito de empresas." Revista do BNDES, Rio de Janeiro, n. 34, p. 133-180, dez.

Aoki, V. C. G.; Badalotti, R. M. (2014) "Dificuldades e perspectivas no acesso de micro e pequenas empresas a linhas de crédito públicas: o caso de Chapecó." Revista de Administração Pública. Rio de Janeiro, v. 48, n. 5, p. 1305-1327. Araujo, A. G. (2004) "Sistemas de garantia no mundo e no Brasil." In: SANTOS, C. A. (Org). Sistema Financeiro e as Micro e Pequenas Empresas: diagnósticos e perspectivas. Brasília: SEBRAE, p. 81-89. 
Azevedo, C. M.; Shikida, P. F. A. (2004) "Assimetria de informação e o crédito agropecuário: o caso dos cooperados da Coamo-Toledo (PR)." Revista de Economia e Sociologia Rural. Rio de Janeiro, v. 42, n. 2, p. 267-292.

BNDES - Banco Nacional de Desenvolvimento Econômico e Social. (2016) "Estatísticas por produto, porte de empresa e forma de apoio.". Disponível em: http://www.bndes.gov.br/wps/portal/site/home/transparencia/estatisticasoperacionais/estatisticas-produto-porte-apoio. Acesso em: 19/11/2016.

Braga, M. B. (1999) "Algumas considerações teóricas e implicações de correntes da relação contratual entre credor e devedor sob a hipótese de existência de assimetria de informação." In: Encontro Nacional de Economia da ANPEC, 27, 1999. Anais... Belém, PA: ANPEC.

Camargo, J. M.; Reis, M. C. (2005) "Desemprego: o custo da desinformação." Revista Brasileira de Economia. Rio de Janeiro, v. 59, n. 3, p. 381-425.

Carvalho, C. E.; Abramovay, R. (2004) "O difícil e custoso acesso ao sistema financeiro nacional." In: SANTOS, C. A. (Org). Sistema Financeiro e as Micro e Pequenas Empresas: diagnósticos e perspectivas. Brasília: SEBRAE, p. 17-45.

Chaves, S, S. (2009) "Cooperativismo de crédito e empresas de pequeno porte em arranjos produtivos locais." 236 p. Tese (Doutorado em Economia) - Universidade Federal do Rio Grande do Sul, Porto Alegre, RS.

Chein, F.; Silva, U. M. V. (2014) "Imperfeições no mercado de crédito e racionamento de crédito: uma análise para o setor informal no Brasil." Nova Economia. Belo Horizonte, v. 24, n. 1, p. 103-122.

Costa, O. M. E. (2007) "O arranjo produtivo de calçados de Juazeiro do Norte: um estudo de caso para o estado do Ceará." Tese (Doutorado em Economia). Universidade Federal do Rio de Janeiro (UFRJ). Rio de Janeiro, RJ, 270 p.

Eisenhardt, K.M. (1989) "Agency Theory: an assessment and review." The Academy of Management Review, v. 14, n. 1, p. 57-74.

Feitosa, F. R. F.; Sousa, E. P. (2013) "Índice de sustentabilidade ambiental das empresas de calçados de Juazeiro do Norte, CE." Revista Ciências Administrativas. Fortaleza, v. 19, n. 1, p. 265-306.

Fonseca, J, S; Martins, G. A. (1996) "Curso de Estatística." 6 ed. São Paulo: Atlas. Frascaroli, B. F.; Paes, N. L.; Ramos, F. S. (2010) "A indústria brasileira e o racionamento de crédito: uma análise do comportamento dos bancos sob informações assimétricas."Economia. Brasília, v. 11, n. 2, p. 403-433.

IPECE - Instituto de Pesquisa e Estratégia Econômica do Ceará. (2016) "Perfil Básico Municipal 2016 Juazeiro do Norte.” Fortaleza. Disponível em: http:// 
www.ipece.ce.gov.br/perfil_basico_municipal/2016/Juazeiro_do_Norte.pdf. Acesso em: 15/12/2016.

Jensen, M. C. (1983) "Organization theory and methodology." Accounting Review, v. 58 , n. 2, p. 319-338.

Jensen, M. C.; Meckling, W. H. (1976) "Theory of the firm: managerial behavior, agency costs and ownership structure." Journal of Financial Economics, v. 3, p. 305-360.

Maia, G. B. S. (2009) "Racionamento de crédito e crise financeira: uma avaliação keynesiana." Revista do BNDES, Rio de Janeiro, n. 31, p. 61-83, jun.

Martinez, A. L. (1998) "Agency theory na pesquisa contábil.” In: Encontro da Associação Nacional de Programas de Pós-Graduação em Contabilidade, 22, 1998. Anais... Foz do Iguaçu, PR: ANPAD.

MATIAS, M. N. (2009) "A assimetria informacional no financiamento das micro e pequenas empresas." Gestão, p. 56-60. Disponível em: http://www.occ.pt/fotos/ downloads/files/1253203347_56a60_gestao_final.pdf. Acesso em: 19/11/2016.

Pindyck, R. S.; Rubinfeld, D. L. (2013) “Microeconomia.” 8a ed. São Paulo: Pearson Education do Brasil.

Rocha, I.; Pereira, A. M.; Bezerra, F. A.; Nascimento, S. (2012) "Análise da produção científica sobre teoria da agência e assimetria da informação." REGE. São Paulo, v. 19, n. 2, p. 327-340.

Santos, C. A. (2004) "Assimetria de informações e racionamento da oferta de crédito." In: SANTOS, C. A. (Org). Sistema Financeiro e as micro e pequenas empresas: diagnósticos e perspectivas. Brasília: SEBRAE, p. 61-64.

SEBRAE - Serviço Brasileiro De Apoio Às Micro E Pequenas Empresas. (2014) “Participação das micro e pequenas empresas na economia brasileira."Brasília, DF.

Stiglitz, J.; Weiss, A. (1981) Credit rationing in markets with imperfect information. American Economic Review, v. 71, p. 393-410.

Ventura, E. C. (2002) "A evolução do crédito: da antiguidade aos dias atuais."1.ed. Curitiba: Juruá.

Vieira, A. A. (2010) "O impacto da informação assimétrica na concessão de crédito: uma aplicação de modelos mistos." In: Congresso da Sociedade Brasileira de Economia, Administração e Sociologia Rural, 48, 2010. Anais... Campo Grande, MS: SOBER.

Zica, R. M. F.; Martins, H. C. (2008) "Sistema de garantia de crédito para micro e pequenas empresas no Brasil: proposta de um modelo." Revista de Administração Pública. Rio de Janeiro, v. 42, n. 1, p. 181-204. 